\title{
Computational and physical simulation of fluid flow inside a beam blank continuous casting mold
}

\author{
Johne Jesus Mol Peixoto ${ }^{a, *}$, Weslei Viana Gabriel ${ }^{a}$, Leticia Queiroz Ribeiro ${ }^{a}$, \\ Carlos Antônio da Silva ${ }^{a}$, Itavahn Alves da Silva ${ }^{a}$, Varadarajan Seshadri ${ }^{\mathrm{b}}$ \\ a Department of Metallurgical Engineering/REDEMAT, Federal University of Ouro Preto, Ouro Preto, Brazil \\ ${ }^{\mathrm{b}}$ Department of Metallurgical Engineering, Federal University of Minas Gerais, Belo Horizonte, Brazil
}

\section{A R T I C L E I N F O}

\section{Article history:}

Received 16 October 2015

Received in revised form 7 January 2016

Accepted 12 February 2016

Available online 17 February 2016

\section{Keywords:}

Beam blank

Fluid flow

Continuous casting

Near net shapes

PIV

\begin{abstract}
A B S T R A C T
The main features of the flow field inside a beam blank continuous casting mold have been assessed through mathematical and physical modeling techniques. Experimental techniques such as particle dispersion through addition of dye and particle image velocimetry have been used in a physical model of the mold to assess the flow pattern. Different combinations of nozzle geometry and throughput have been employed and the experimental results have been analyzed. In the case of two tubular nozzles, which should ensure good thermal and flow symmetry, six vortices were observed in the mold, two near the web and two in each of the flanges. Increasing the flow rate of the fluid from $100 \mathrm{~L} / \mathrm{min}$ to $150 \mathrm{~L} / \mathrm{min}$ leads to a change from $0.74 \mathrm{~m}$ to $0.84 \mathrm{~m}$ in the jet penetration depth. However even a $67 \%$ increase of the nozzle cross section did not affect this parameter significantly. Experiments with one single tubular nozzle ( $53.2 \mathrm{~mm}$ inside diameter) were also carried out and the resulting flow asymmetry has been characterized. The difference in the fluid velocities at the filets could lead to unequal solid shell growth. The depth of jet penetration is larger than mold nominal length $(0.8 \mathrm{~m})$. Fluid flow structure as determined by PIV measurements and CFD simulations show a good agreement.
\end{abstract}

(c) 2016 Elsevier B.V. All rights reserved.

\section{Introduction}

Actual experimental trials to determine optimum conditions of operation in the continuous casting unit can lead to interruptions in the production schedule and consequently loss of productivity and profitability. Mathematical analysis and physical modeling experiments in the laboratory are an alternative to achieve optimum conditions for achieving increased productivity and improved quality of the product. Hibbeler et al. (2009) developed a mathematical model for simulating the temperature profile and the stress/deformation field inside the solidifying shell in a beam blank continuous casting mold. This model is also capable of throwing light on the mechanism of crack formation at the filet region, due to a combination of a thinner shell, mechanical stress and an extended air gap.

Lee et al. (2000) had observed that the air gap was mainly formed in the flange-tip, which retards the shell development in this region. The irregular advance of the solidifying shell is caused by nonuni-

\footnotetext{
* Corresponding author.

E-mail address: johnepeix@yahoo.com.br (J.J.M. Peixoto).
}

form heat transfer and the stress concentration in the thinnest part of the solidified shell, implying a higher probability of occurrence of cracks. Zhao et al. (2014) detected that a large temperature difference between the filet and other regions on the surface can cause longitudinal cracks at the fillet, and an optimization in the cooling system can improve the quality of the beam blank.

The flow field inside the mold is known to impact the steel internal cleanliness and the growth of the shell. In the conventional continuous casting, the flow field is influenced by mold geometry, casting velocity, nozzle geometry as well as immersion depth. Chen et al. (2012a) has highlighted these effects for the beam blank casting process. Yang et al. (2006) considered the effects of a growing shell on the flow and found it to be significant due to the localized small flow section.

Chen et al. (2012a) have performed studies on tubular nozzles and concluded that they cause deep steel penetration depths and small meniscus velocity. This could lead to a decrease in the likelihood of inclusion flotation and also decreasing entrapment of mold powder by the bulk metal. The authors suggest a nozzle immersion depth in the range of $50-100 \mathrm{~mm}$.

The usual arrangement of SEN for beam blank continuous casting employs two tubular nozzles, at the center of each flange. To 

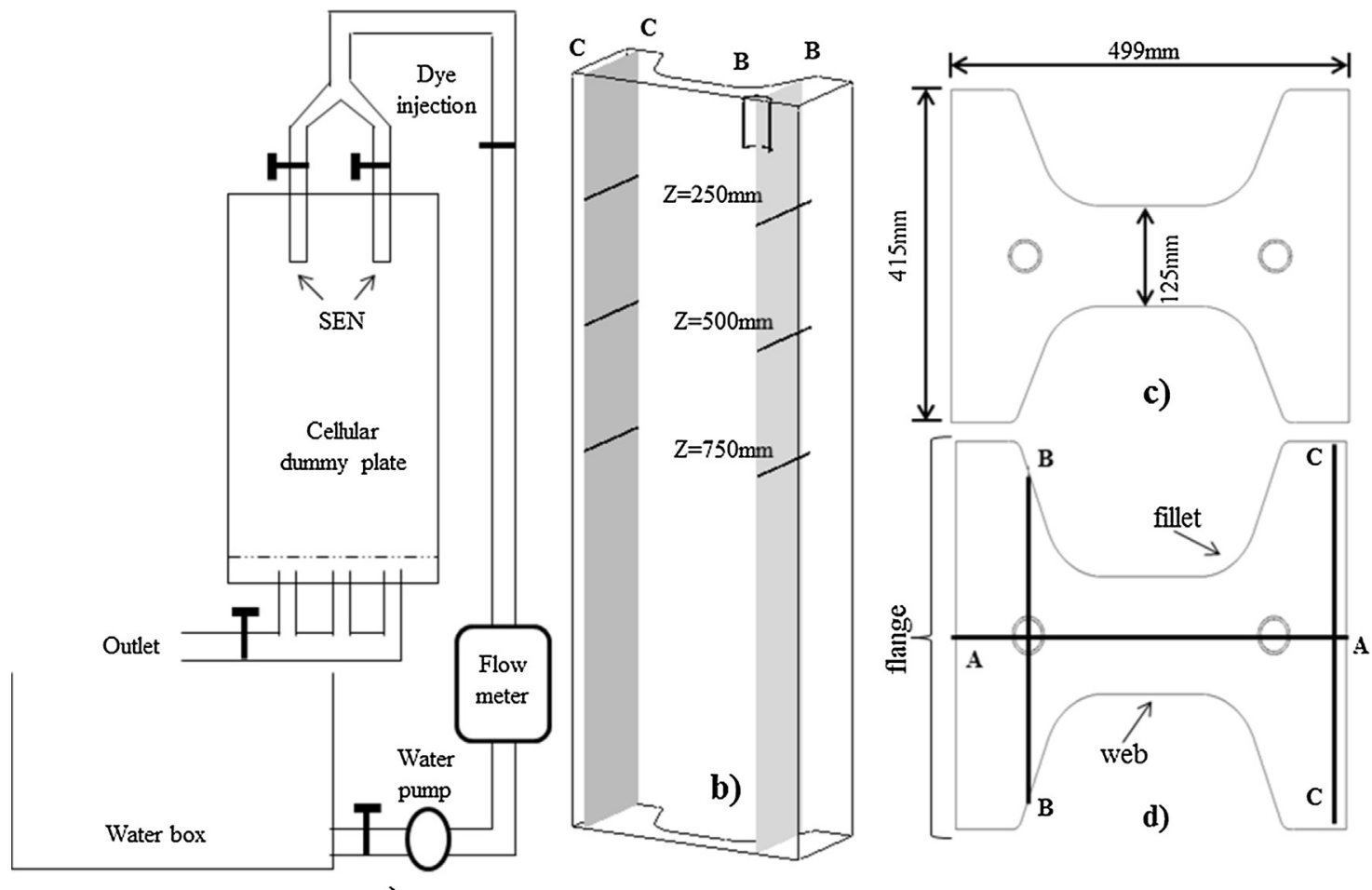

a)

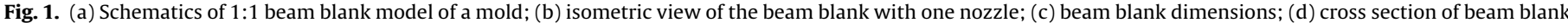
depicting cutting planes AA, BB, and CC.

improve the product quality and productivity, other configurations have been suggested. Yang et al. (2004) analyzed the fluid flow in beam blank mold fitted with two nozzles, and found that the configuration of a SEN with a frontal and two lateral outlets, with an angle of $120^{\circ}$ between the outlets and a port inclination of $+15^{\circ}$ lead to better inclusion removal from molten steel. According to Chen et al. (2012b), in the case of a three hole SEN, the steel penetration depth would be reduced with a substantial change in the velocity at the free surface accompanied by a more intense fluctuation. This helps in the melting of the mold powder and leads to a better absorption of non-metallic inclusions. The recommended port inclination angle in this case was $+9^{\circ}$.

Employment of two nozzles in the mold is complex and requires a good flow control as compared to a single nozzle arrangement. Nozzleís mispositioning can stimulate non-symmetrical flow leading to product defects. On the other hand, a single nozzle feeding can result in a high liquid steel velocity in the mold, which is harmful to the shell integrity and meniscus stability. De Santis et al. (2014) proposed in the case of beam blank continuous casting, feeding the metal with only one nozzle. Multi-holes nozzle geometries have been analyzed through mathematical modeling. A nozzle with a $50 \mathrm{~mm}$ diameter throat, a $50 \mathrm{~mm} \times 60 \mathrm{~mm}$ elliptical lateral port inclined $25^{\circ}$ downwards, and a $20 \mathrm{~mm}$-diameter bottom hole, has been proposed as the best SEN design under their operational conditions.

As it can be seen from the above survey the flow field inside the mold is fundamental in controlling the product quality and productivity and hence should be optimized by controlling different variables relevant to the process. In this contribution, mathematical and physical modeling of flow field inside a beam blank mold have been carried out and the effect of nozzle geometry, casting velocity and other parameters have been analyzed.

\section{Methodology}

Experiments were conducted in a physical model (acrylic) with the following dimensions: $499 \mathrm{~mm} \times 415 \mathrm{~mm} \times 125 \mathrm{~mm}$ with the mold length of $1.5 \mathrm{~m}$. Fig. 1 represents the physical model constructed with a scale of $1: 1$ of the prototype of beam blank mold. The physical model is based on similarity criteria between the industrial steel system and a model employing water as the working fluid. This has been discussed by Szekely and Ilegbusi (1989). According to them, the isothermal flow similarity is achieved if Reynolds and Froude dimensionless groups are taken into consideration. A model with $1: 1$ scale is preferred considering the physical properties of water $\left(25^{\circ} \mathrm{C}\right)$ and steel $\left(1600^{\circ} \mathrm{C}\right)$ such as dynamic viscosity and density. Hence the model volumetric flow rate is equal to the volumetric flow rate of steel in the industrial unit. However the effect of a growing shell and the convective motion due to variation of temperature in the steel pool in the mold could not be taken in consideration since the fluid used in the physical model is water in isothermal conditions. The techniques involved in the experiments with the physical model were as follows.

A continuous flow of dye was injected in the nozzle. Dye dispersion was followed by taking a movie from which different frames for different times could be detached. In addition to dispersion, the penetration depths of liquid jet were also measured.

General aspects of flow field can be observed by focusing light over the small suspended plastic particles (Goodyear SH6, roughly the same density as water). A laser sheet for visualization can be prepared by directing a laser beam over a cylindrical lens. The displacement of these particles as a function of time gives important information regarding flow structure and location of macroscopic eddies. The schematics of the beam blank physical model can be seen in Fig. 1(a). 


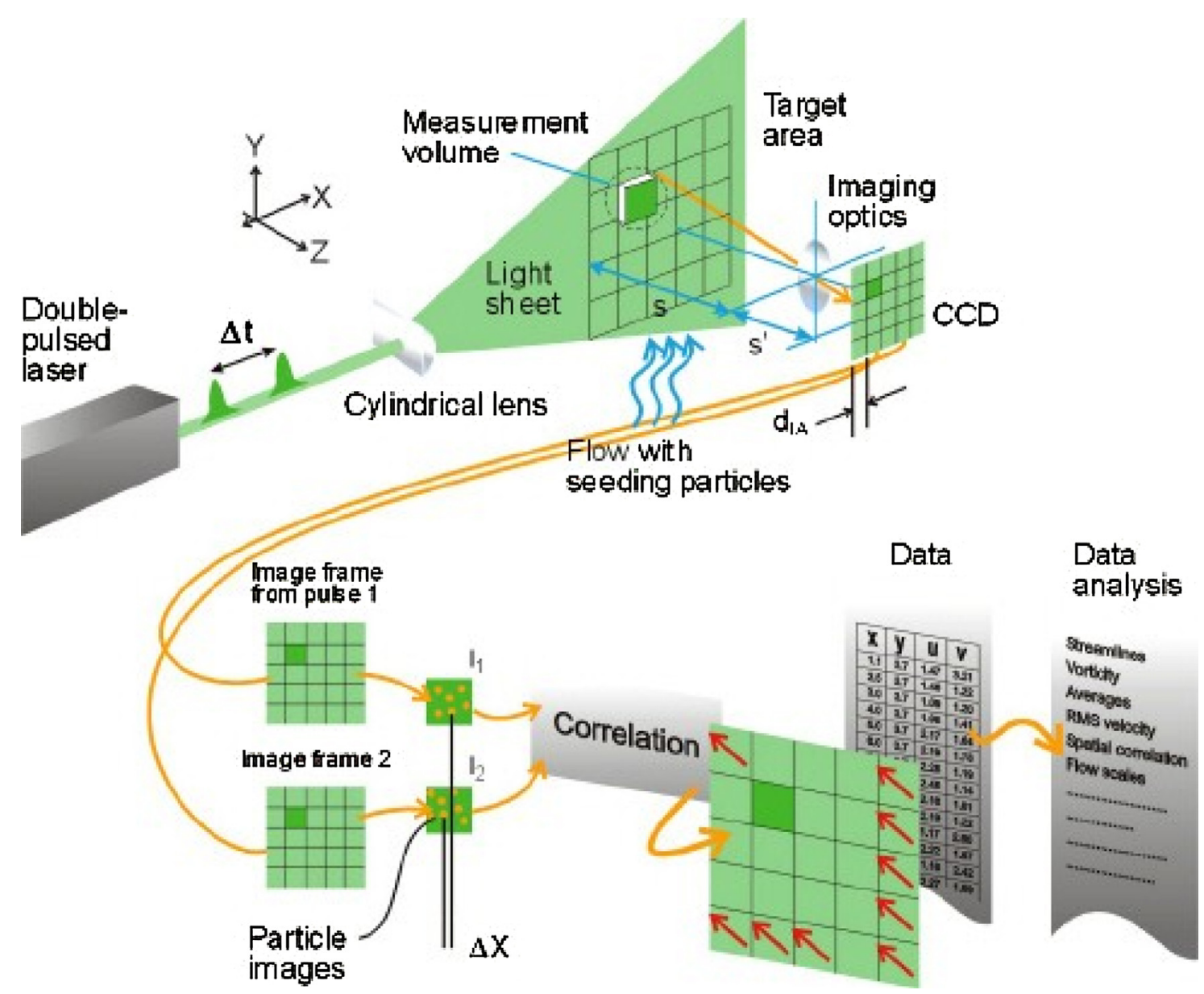

Fig. 2. PIV (Particle Image Velocimetry) according to DANTEC ${ }^{\circledR}$.

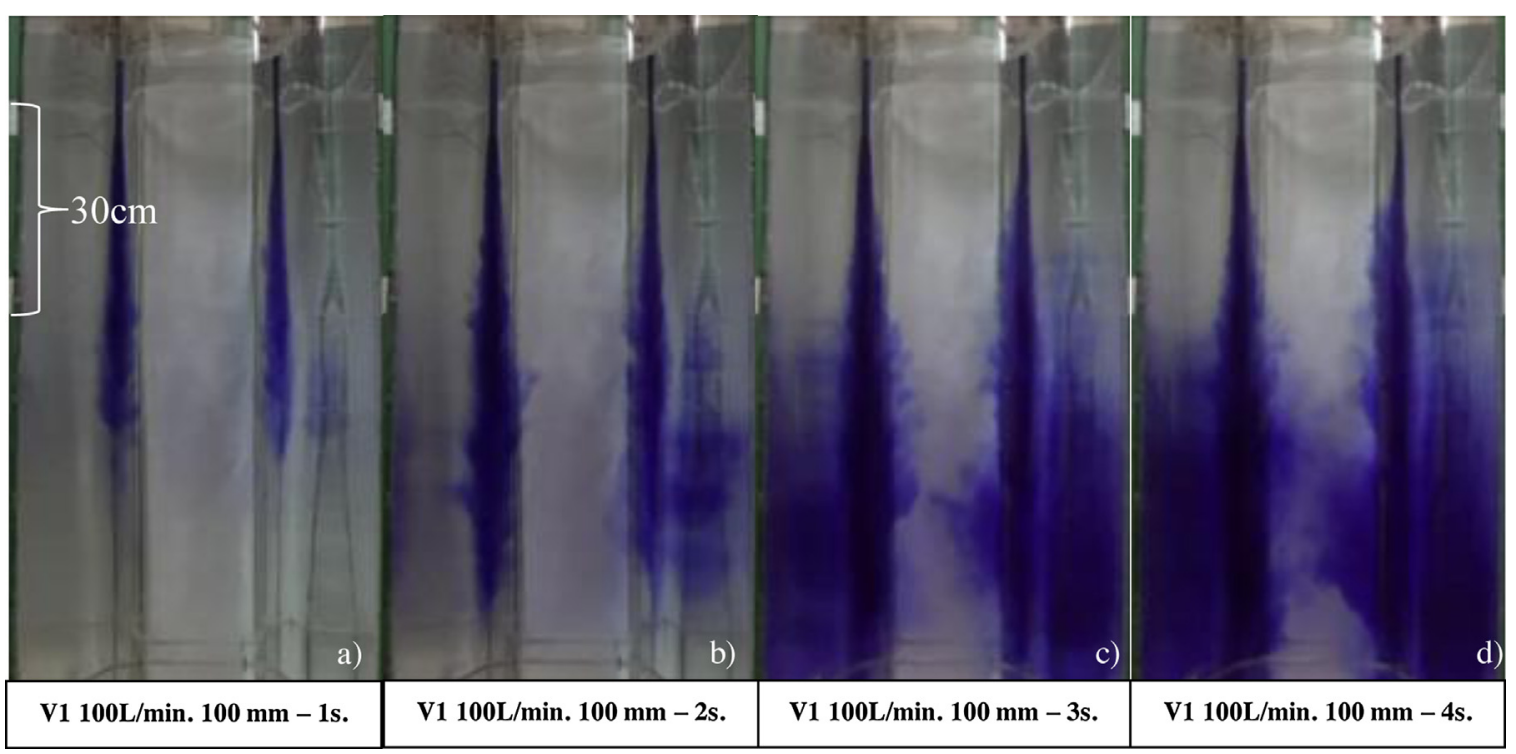

Fig. 3. Spreading of a dye injected at the tubular nozzle as a function of time. Type 1 nozzle, liquid flow rate of $100 \mathrm{~L} / \mathrm{min}-(\mathrm{a}) t=1 \mathrm{~s}$; (b) $t=2 \mathrm{~s} ;(\mathrm{c}) t=3 \mathrm{~s}$ e (d) $t=4 \mathrm{~s}$.

Quantitative analysis of flow field was made possible through the adoption of PIV technique (Particle Image Velocimetry), developed by DANTEC $^{\circledR}$ (Fig. 2). More details of this technique can be found elsewhere (http://www.dantecdynamics.com/ measurement-principles-of-piv). PIV was employed to evaluate the flow field in the sections BB (crossing the middle of the valve) and CC (25 mm from the surface of flange), as given in Fig. 1(b) and (d), ranging from the meniscus to $0.8 \mathrm{~m}$ deep down the mold. Due to mold curvature PIV measurements have been limited to these selected sections. 

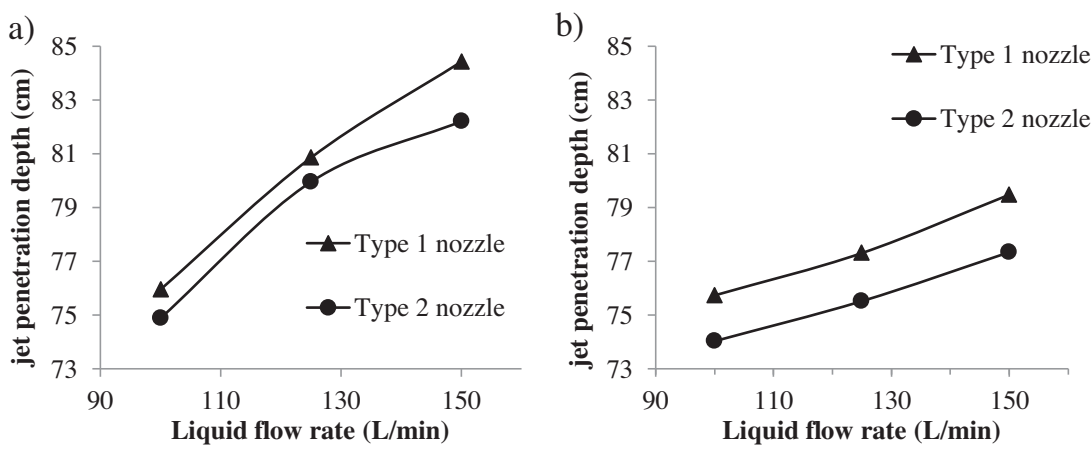

Fig. 4. Comparison between values of penetration depth (a) dye dispersion at $2 \mathrm{~s}$; (b) CFD results.

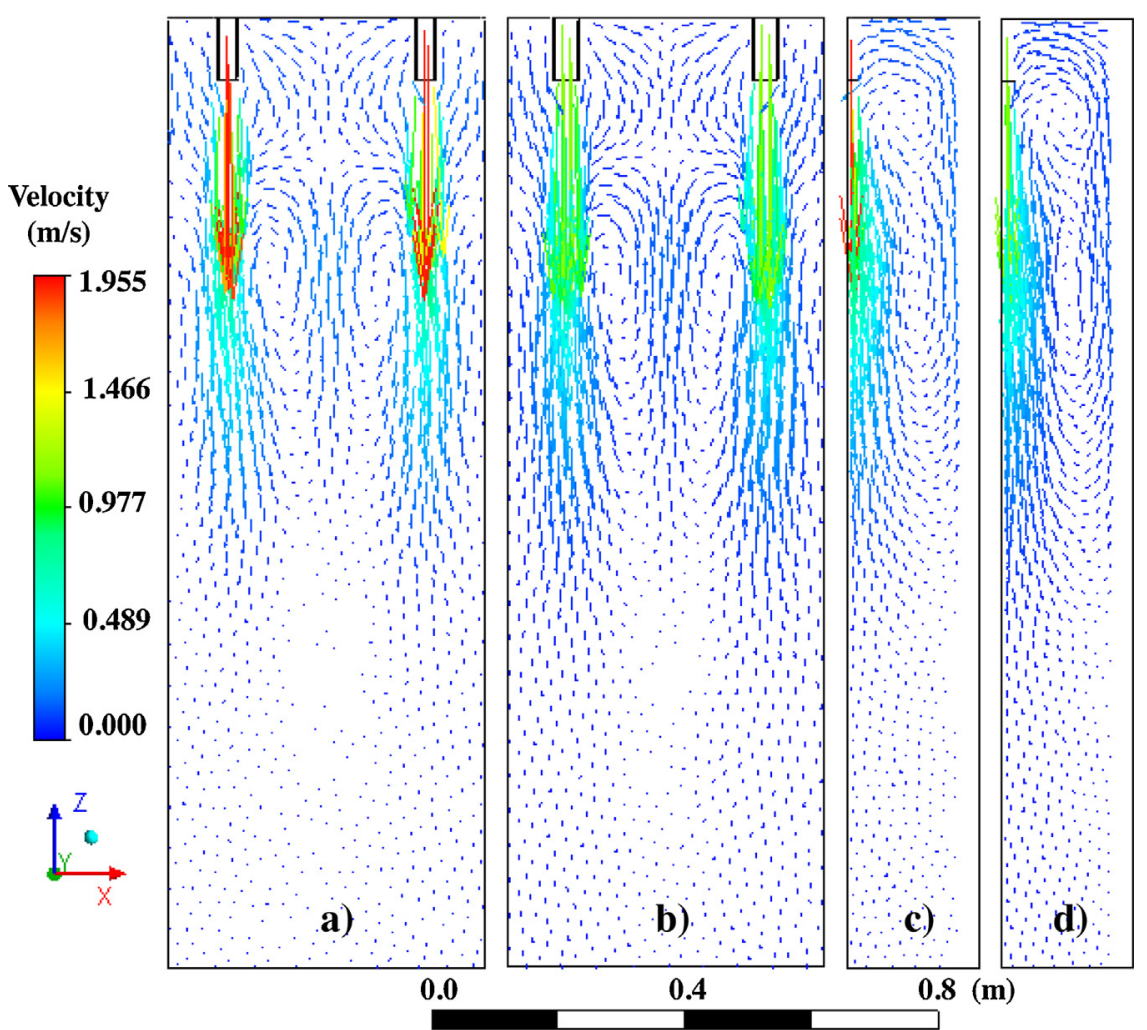

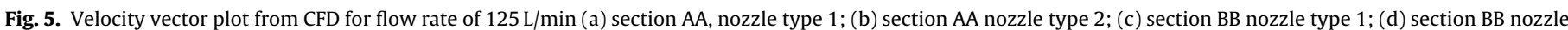
type 2.

The experimental results from the physical model has the objective of substantiating the results of CFD modelling, so that the latter can be used as a reliable tool for improvement and optimization of the process. CFD modeling was accomplished by using Ansys ${ }^{\circledR}$ CFX 15.0 , assuming isothermal steady state conditions. The standard $k$ $€$ turbulence model was used. Then the following equations have been solved:

Continuity:

$\frac{\partial \rho}{\partial t}+\nabla \bullet(\rho U)=0$

Navier Stokes equation:

$\frac{\partial \rho U}{\partial t}+\nabla \bullet(\rho \mathrm{U} \otimes \mathrm{U})-\nabla \bullet\left(\mu_{\text {eff }} \nabla \mathrm{U}\right)=-\nabla p+\nabla \bullet\left(\mu_{\text {eff }} \nabla \mathrm{U}\right)^{T}+B$

Effective viscosity equation:

$\mu_{\text {eff }}=\mu+\mu_{t}$
Equations of the k- $\varepsilon$ turbulence model:

$\frac{\partial(\rho k)}{\partial t}+\nabla \bullet(\rho U k)=\nabla \bullet\left[\left(\mu+\frac{\mu_{t}}{\sigma_{k}}\right) \nabla K\right]+P_{k}-\rho \varepsilon$
$\frac{\partial(\rho \varepsilon)}{\partial t}+\nabla \bullet(\rho U \varepsilon)=\nabla \bullet\left[\left(\mu+\frac{\mu_{t}}{\mu_{\varepsilon}}\right) \nabla \varepsilon\right]+\frac{\varepsilon}{k}\left(C_{\varepsilon 1} P_{k}-C_{\varepsilon 2} \rho \varepsilon\right)$

$\mu_{t}=C_{\mu} \rho \frac{k^{2}}{\varepsilon}$

Here $\rho$ is the liquid density $(\mathrm{Kg} / \mathrm{m} 3)$; $\mathrm{t}$ is the time $(\mathrm{s}) ; \nabla$ is the Nabla operator; $U$ is the average velocity $(\mathrm{m} / \mathrm{s}) ; \mu_{\text {eff }}$ is the effective viscosity (Pa.s); $B$ is the body force $(\mathrm{N}) ; \mu$ is the molecular viscosity; $\mu_{t}$ is the turbulent viscosity (Pa.s); $k$ is the turbulent kinetic energy $(\mathrm{m} 2 / \mathrm{s} 2) ; P_{k}$ is the rate of production of kinetic energy due to viscosity and buoyancy effects; $\varepsilon$ is the rate of dissipation of turbulent kinetic energy (m2/s3); $C_{\varepsilon 1}, C_{\varepsilon 2}, C_{\mu}, \sigma_{k}$ are constants.

Boundary conditions are as follows: 


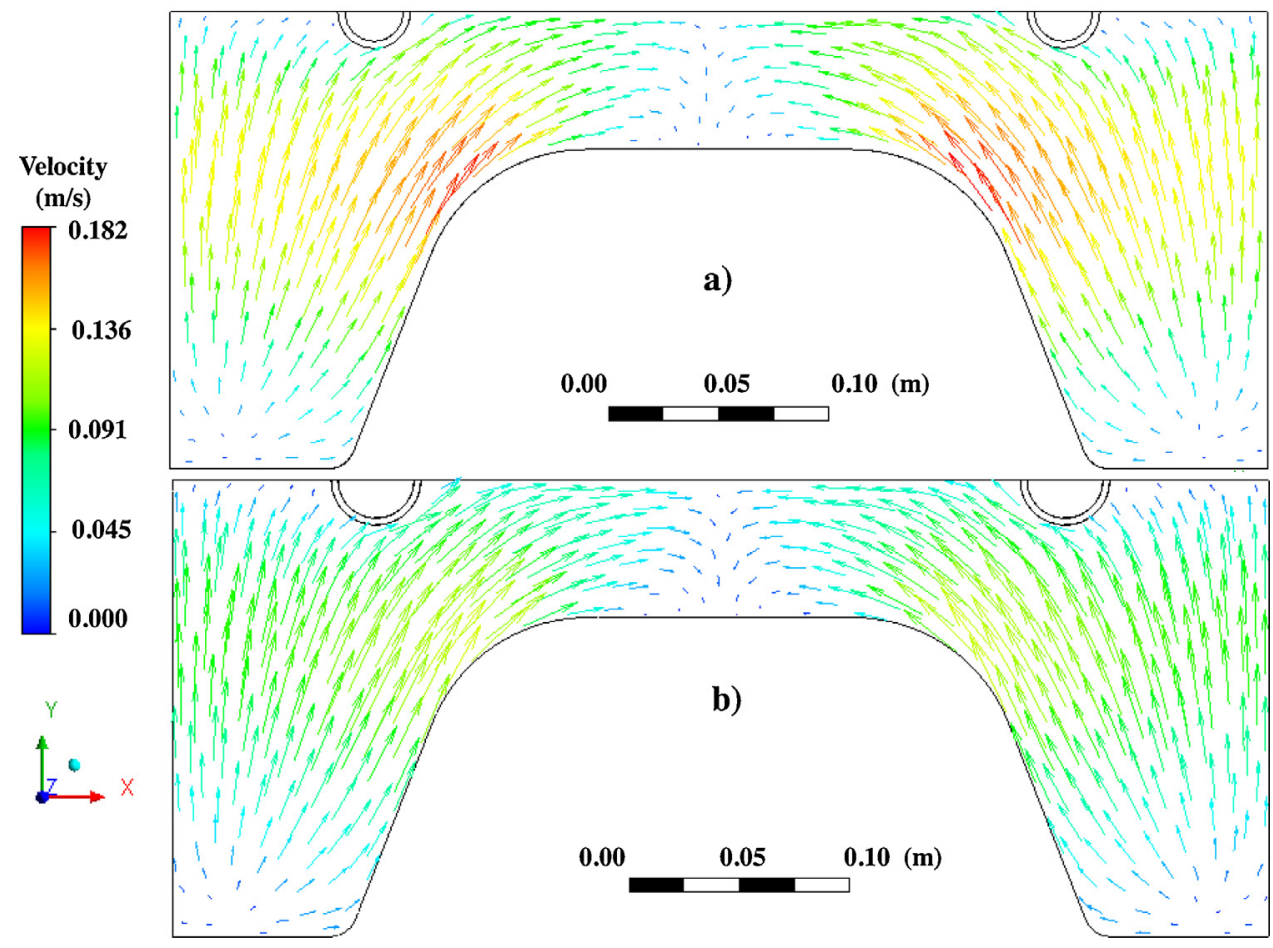

Fig. 6. Velocity vector plot at the meniscus region for liquid flow rate of $125 \mathrm{~L} / \mathrm{min}$ : (a) type 1 nozzle and (b) type 2 nozzle.
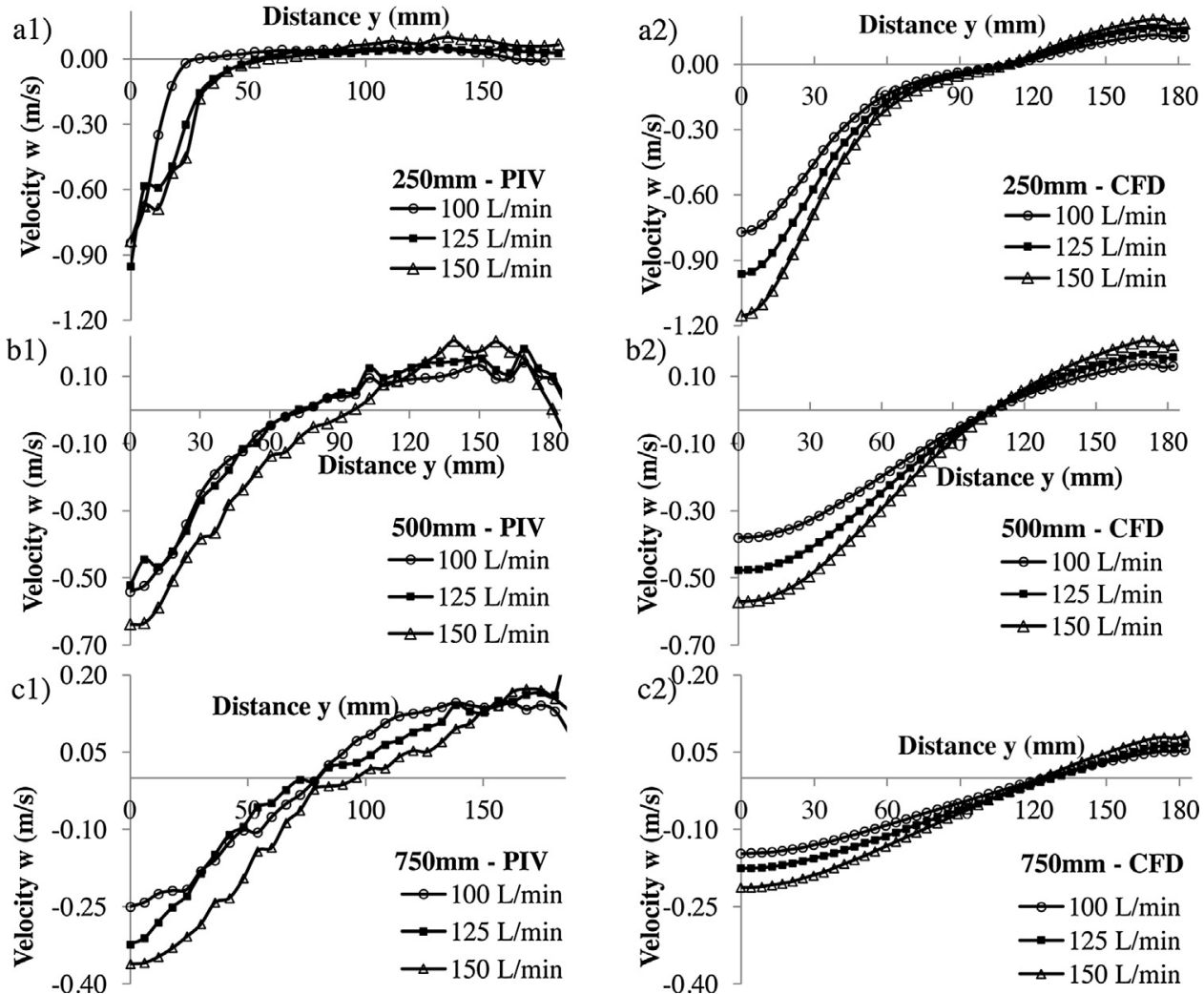

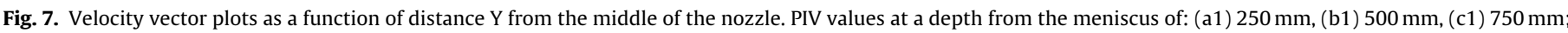
CFD values at a depth from meniscus of (a2) $250 \mathrm{~mm}$, (b2) $500 \mathrm{~mm}$, (c2) $750 \mathrm{~mm}$. Nozzle type 1.

- Non slipping condition at each liquid solid interface, nozzle and walls. Then $U, k$ and $\varepsilon$ values are taken as zero at these locations.

- Free surface condition at liquid atmosphere interface, with Uw equal to zero.
- An average velocity at entry nozzle can be estimated from the assumed throughput $(1.667 \mathrm{~kg} / \mathrm{s} ; 2.083 \mathrm{~kg} / \mathrm{s}$ e $2.5 \mathrm{~kg} / \mathrm{s}$ for linear casting velocities of $0.78 \mathrm{~m} / \mathrm{min} ; 0.98 \mathrm{~m} / \mathrm{min}$ e $1.2 \mathrm{~m} / \mathrm{min}$, respec- 


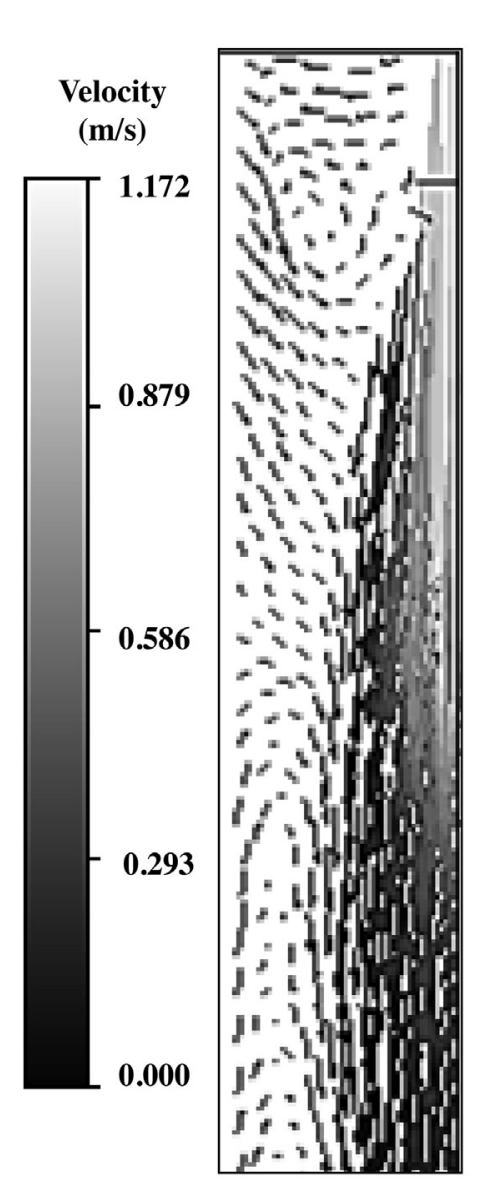

(a) CFD

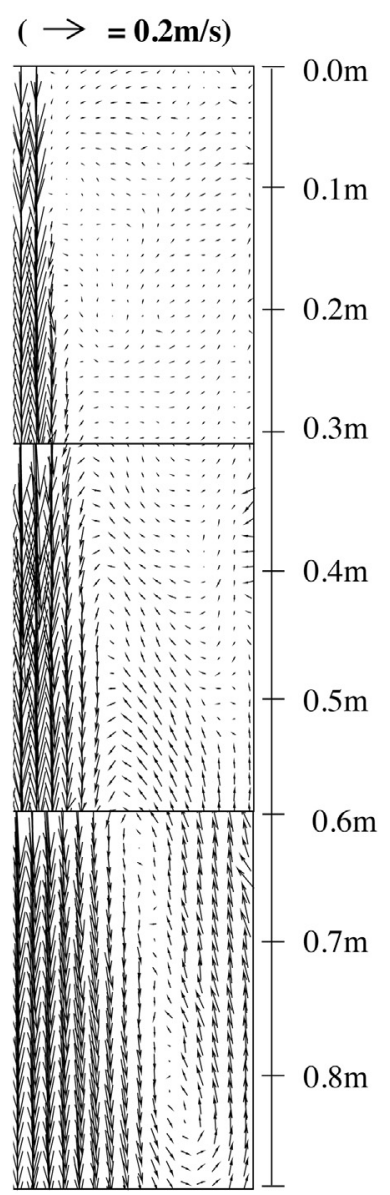

(b) PIV

Fig. 8. Velocity vector plot at plane BB for flow rate of $125 \mathrm{~L} / \mathrm{min}$ : (a) CFD simulation; (b) physical simulation-PIV.

tively); accordingly average values of $k$ and $\varepsilon$ have been estimated assuming (Li et al., 2001):

$k=0.01 V^{2}$

$\varepsilon=\frac{k^{1.5}}{R}$

where $V$ is the average liquid velocity at the nozzle inlet and $R$ is the nozzle internal radius.

A simpler approach to achieve symmetrical flow in a beam blank mold is by using twin tubular nozzles. One single nozzle always results in a non-symmetrical flow. The two cases are detailed here. For two nozzles, symmetrical flow, a combination of tubular nozzles of different inside diameters (type 1: $26.7 \mathrm{~mm}$; type $2: 34.6 \mathrm{~mm}$ ) and casting velocities $(100 \mathrm{~L} / \mathrm{min}, 125 \mathrm{~L} / \mathrm{min}$ and $150 \mathrm{~L} / \mathrm{min}$ ) have been employed. These volumetric liquid flow rates correspond to the linear casting velocities namely $0.78 \mathrm{~m} / \mathrm{min}$; $0.98 \mathrm{~m} / \mathrm{min}$ and $1.2 \mathrm{~m} / \mathrm{min}$, respectively. Nozzle depth of immersion was kept at $100 \mathrm{~mm}$. Physical and numerical simulations for one nozzle non-symmetrical flow have been carried out considering one tubular nozzle with $53.2 \mathrm{~mm}$ of inside diameter (type 3 nozzle) at the same flow rates. The results have been compared with those from an arrangement with two nozzles with $26.7 \mathrm{~mm}$ inside diameter (type 1 nozzle).

\section{Results and discussion}

\subsection{Two nozzles, symmetrical flow}

Fluid flow characteristics have been determined at two cutting planes, AA and BB as shown in Fig. 1(b) and (d). The maximum depth reached by the incoming liquid jet was determined using dye dispersion technique in the mold. This technique had been used by Chen et al. (2012b) and Zhang et al. (2014). Frames obtained from dye dispersion experiments, are represented in Fig. 3. It was observed that after roughly $2 \mathrm{~s}$, dye dispersion was mainly in the horizontal direction, with a minor inertial component pushing the dye toward the bottom. A frame of dye dispersion at $2 \mathrm{~s}$ of injection was used to define the steel penetration depth.

Fig. 4 shows a comparison of jet penetration depth as determined from dye dispersion experiments and inferred from CFD simulations. Results from physical modeling suggest that the main influencing factor is the liquid flow rate-Fig. 4(a). Enlarging the nozzle diameter on $67 \%$ (Type 1 to Type 2 ) did not result in sizable reduction of the depth of penetration. CFD simulations, given in Fig. 4(b), show a lesser influence of flow rate in the jet penetration depth, which can be attributed to the assumption of a fixed free slipping surface. This boundary condition leads to the prediction of a weaker vortex than the actual one happening in the process and also reduced downward flow velocity (Li et al., 2001). In general it can be concluded that the results of physical model experiments conform to CFD model results. 

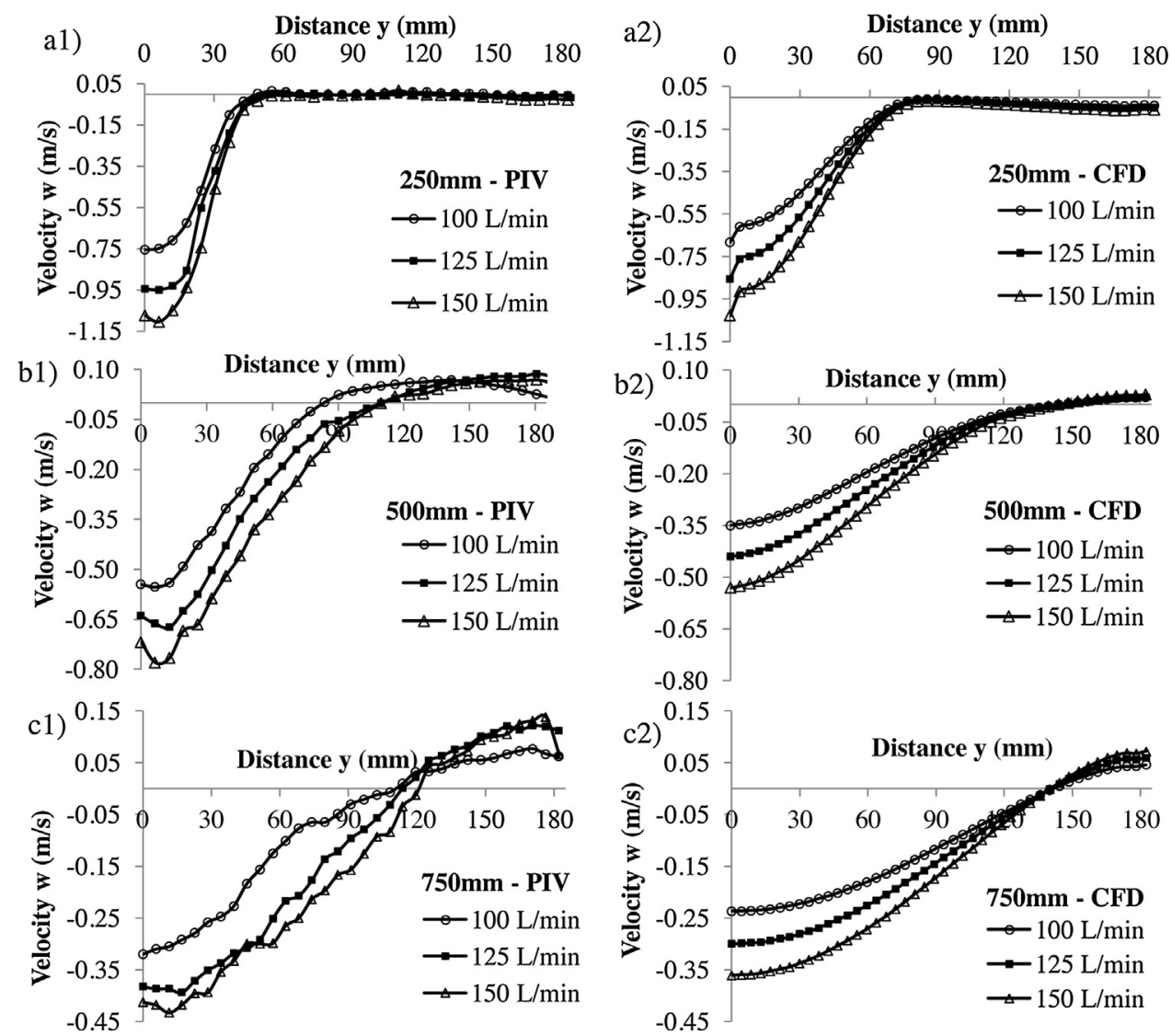

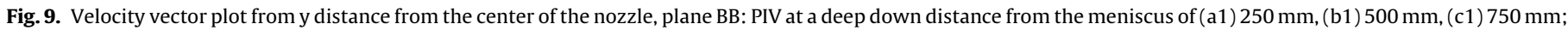
CFD simulation at a deep down distance from the meniscus of (a2) $250 \mathrm{~mm}$, (b2) $500 \mathrm{~mm}$, (c2) $750 \mathrm{~mm}$. Nozzle type 3.

Chen et al. (2012a) have also found that increasing flow rates leaded to increasing steel penetration depth. However values obtained by them were greater than $1 \mathrm{~m}$ for casting velocities of $0.7 \mathrm{~m} / \mathrm{min}$ to $1.3 \mathrm{~m} / \mathrm{min}$ in the case of a beam blank mold of dimensions $550 \mathrm{~mm} \times 450 \mathrm{~mm} \times 90 \mathrm{~mm}$, using tubular nozzles with internal diameters from $40 \mathrm{~mm}$ to $75 \mathrm{~mm}$ respectively. The difference can be ascribed to the mold geometry, a narrower web and a longer flange impairing the fluid flow toward the web and then keeping the flow restricted to the flange regions.

CFD simulations highlight similar features of the flow field. Fig. 5(a) and (b) shows that the liquid jet spreads itself toward the bottom and then gets back to the surface, generating two eddies in the web region. The liquid moves to the liquid jet region and then is dragged down. Also in Fig. 5, one can notice the presence of two eddies close to the surface. Liquid from these eddies moves from the flange to the web and then down into the jet. This behavior is similar to that found by Chen et al. (2012b). Six eddies were observed by Zhang et al. (2014).

No sizable effect on the overall fluid flow was observed, when changing the nozzle inside diameter from $26.7 \mathrm{~mm}$ to $34.6 \mathrm{~mm}$. This is seen in Fig. 5(a) and (b)-plane AA-and in Fig. 5(c) and (d)-plane $B B$. Fluid behavior is similar for both nozzles, although jet average velocity decreases for larger nozzle as expected. Zhang et al. (2014) also observed that larger SEN inner diameter would lead to smaller liquid level fluctuation and an increase in the inclusion removal rate.

Fig. 6 shows a velocity plot at the meniscus region. One can notice a flow from the flanges to the central part of the web. Higher values of velocity were observed close to the fillets. Smaller nozzle diameter leads to higher velocities. Lee et al. (1998) pointed out that the recirculatory flow at the web and at the tip of the flange influences the growth of steel shell. The growth of steel shell at the filet regions is slower during the early solidification stages. Also the growth of solid shell at the filet region and at the middle of the web can be retarded by direct impingement of the steel jet coming from the nozzle upon the shell.

It is important to remember that very low velocities at the meniscus region are related to smaller rate of powder melting, inclusion flotation and removal by the top slag. On the other hand excessive velocity at the meniscus can lead to meniscus oscillation and slag entrapment. De Santis et al. (2014) suggested a meniscus velocity around $0.30 \mathrm{~m} / \mathrm{s}$ in order to ensure the required powder melting rate. As it can be seen from Fig. 6, the values of velocity at the meniscus are below this critical value. Enlarging the nozzle inside diameter can further decrease the velocity. This could be related to smaller velocities at the upper recirculation eddies shown in the vector plot of Fig. 5(c) and (d).

Fig. 7 shows the vertical component of velocity in a horizontal measurement line drawn through the plane BB-Fig. 1(d). The measurement lines are $250 \mathrm{~mm}, 500 \mathrm{~mm}$ and $750 \mathrm{~mm}$ deep, down the meniscus. This figure provides a comparison between physical simulation (PIV values, left side) and CFD (right side) modeling results. Larger values of velocity are at the middle region, around the core of the jet coming from the nozzle. Velocities decrease toward the walls, as expected. The smaller velocity values in the region, deep down from the meniscus are due to jet spreading. Increasing flow rates lead to higher jet velocity (negative values) and to recirculation (positive values).

Yang et al. (2006) remarked that with increasing throughputs, the thermal gradient inside the mold also increases as well as the metallurgical length. According to their simulation the linear casting velocity should be kept between $0.85 \mathrm{~m} / \mathrm{min}$ and $1.05 \mathrm{~m} / \mathrm{min}$ 

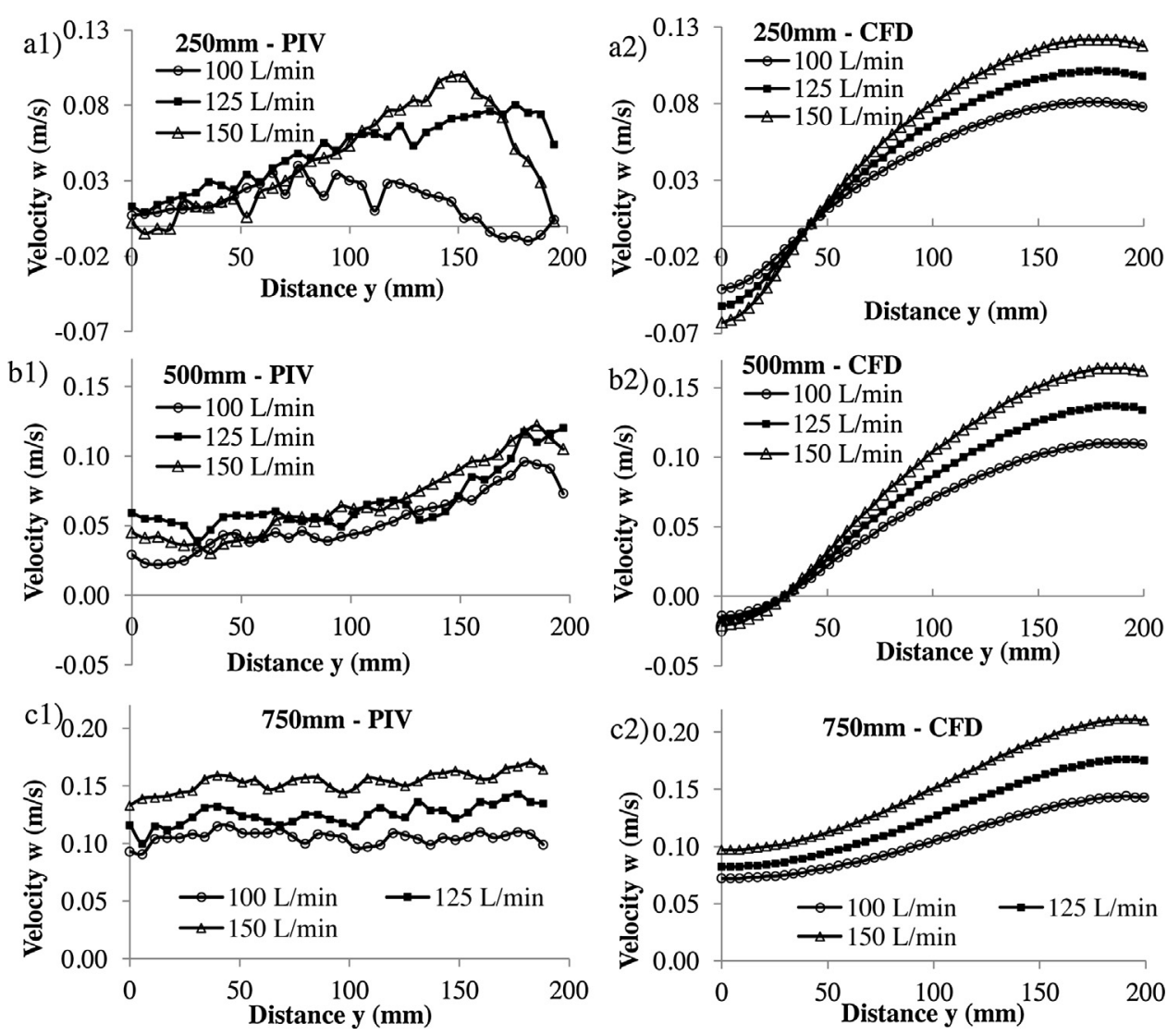

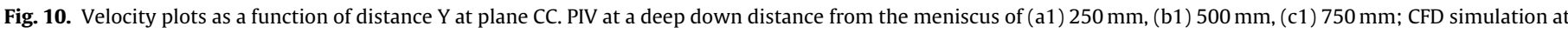
a deep down distance from the meniscus of (a2) $250 \mathrm{~mm}$, (b2) $500 \mathrm{~mm}$, (c2) $750 \mathrm{~mm}$. Nozzle type 3.

in order to ensure productivity rates without compromising on quality and this should not exceed $1.1 \mathrm{~m} / \mathrm{min}$. Chen et al. (2012a) observed that with increasing throughputs, the general aspects of fluid flow inside the mold do not change. However, the steel penetration depth, the meniscus velocity and the surface oscillation do increase. All other parameters being constant, casting velocity should be in the range $0.9 \mathrm{~m} / \mathrm{min}$ to $1.3 \mathrm{~m} / \mathrm{min}$.

It is worth noticing that the change of sign of velocity, as shown in Fig. 7, is an indication of an eddy (from the flange), as already shown in Fig. 5(c) and (d). Plots at the left side of Fig. 7 (PIV values), show that the center of this eddy is located at $75 \mathrm{~mm}$ from the jet core, some $125 \mathrm{~mm}$ from the fillet. In general, the values from physical simulation (PIV) and from CFD simulations are in good agreement.

\subsection{One nozzle non-symmetrical flow}

Data gathered from the flow field have been acquired in three measurement planes: a vertical plane cutting through the web symmetry plane AA, Fig. 1(d); a vertical plane parallel to the flange and cutting through the center of the nozzle, plane BB; and at a plane parallel and at a distance of $25 \mathrm{~mm}$ from the other flange, plane CC. This is shown in Fig. 1(b) and (d).

Fig. 8 shows a comparison between velocity vector plots from physical model (PIV measurements) and numerical CFD modeling at plane BB. The flow structures as depicted from these simulations are quite similar. Velocity values at horizontal lines located at $250 \mathrm{~mm}, 500 \mathrm{~mm}$ and $750 \mathrm{~mm}$ from the meniscus-Fig. 1(b)-, at plane BB determined from experiments in physical model (PIV) and CFD modeling are shown in Fig. 9. Both techniques suggest that the casting speed do not significantly change the overall fluid-flow pattern of the jet. The PIV measurements show larger velocities and narrower jets than those predicted by CFD simulations. In general, there is a good agreement between them proving that the CFD modeling is a reliable tool for this type of process analysis. Velocity values at the middle region of the flange are found to be higher, due to fluid jet coming from the nozzle. Higher throughputs lead to both higher steel jet velocities (downwards) and higher returning (upwards) velocities at the opposite flange.

Fig. 10 represents velocity values obtained from physical model experiments (PIV) and CFD modeling at plane CC-Fig. 1(b)-, at horizontal lines $250 \mathrm{~mm}, 500 \mathrm{~mm}, 750 \mathrm{~mm}$ down the meniscus. As expected, the velocity values are comparatively smaller than in the plane BB. Deeper down from the meniscus, the velocity increases due to the proximity of turning point of the recirculation flow. The smaller values of velocity close to center of the flange, at $250 \mathrm{~mm}$, are due to an eddy located at this region.

Steel penetration depths for flow rates of $100 \mathrm{~L} / \mathrm{min}, 125 \mathrm{~L} / \mathrm{min}$ and $150 \mathrm{~L} / \mathrm{min}$ have been determined. The values are respectively $0.92 \mathrm{~m}, 1.19 \mathrm{~m}$ and $1.29 \mathrm{~m}$ with the type 3 nozzle $(53.2 \mathrm{~mm}$ inside diameter). These values are higher than mold nominal length $(0.8 \mathrm{~m})$. Steel penetration depths in the case of two tubular nozzles (type $1,26.7 \mathrm{~mm}$ of inside diameter) were $0.76 \mathrm{~m}, 0.81 \mathrm{~m}$ and $0.84 \mathrm{~m}$ under the same conditions. Chen et al. (2012a) has made an analysis of fluid flow inside a beam blank mold using two tubular nozzles and has found a penetration depth of $1.09 \mathrm{~m}$ for a casting velocity of $0.9 \mathrm{~m} / \mathrm{min}$. According to these authors, a high value of penetration depth is related to a smaller likelihood of inclusion removal.

According to Fig. 11, the jet from the tubular nozzle reaches the penetration depth and then spreads itself generating vortices in the lower region of the mold. The jet stream then reaches the opposite 


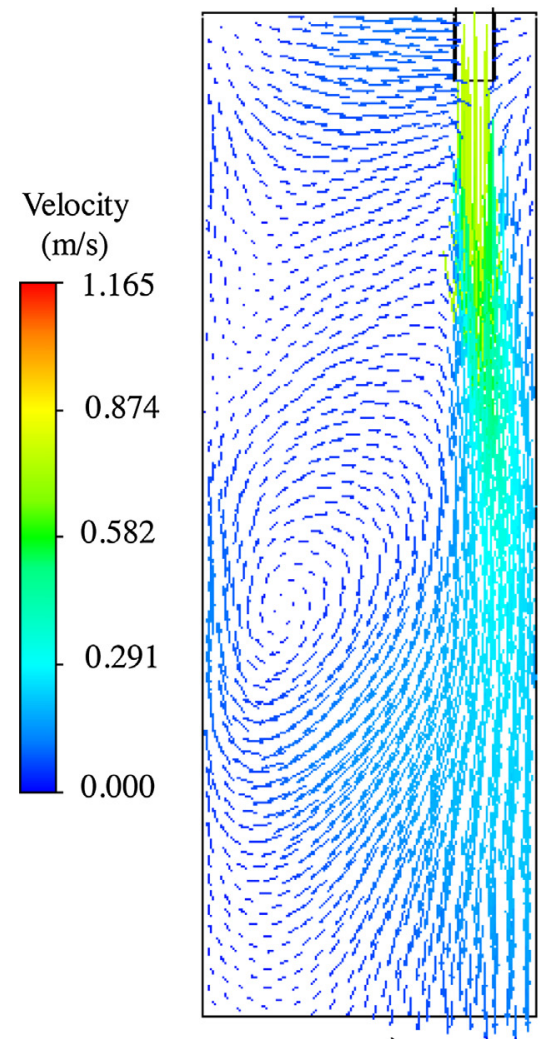

a)

$100 \mathrm{~L} / \mathrm{min}$

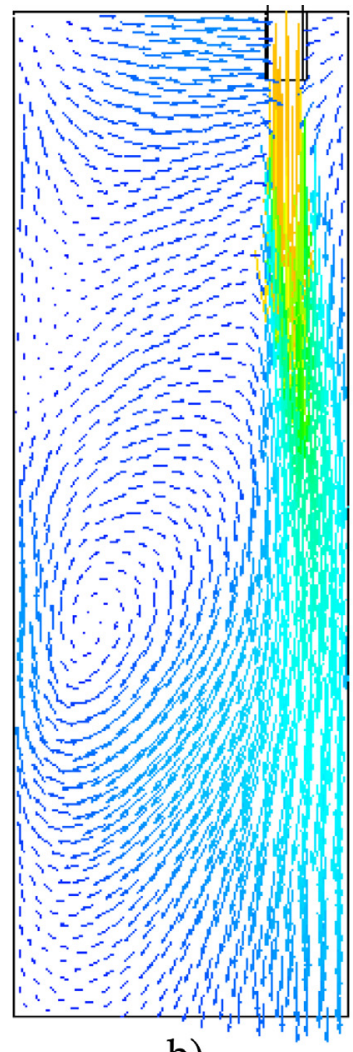

b)

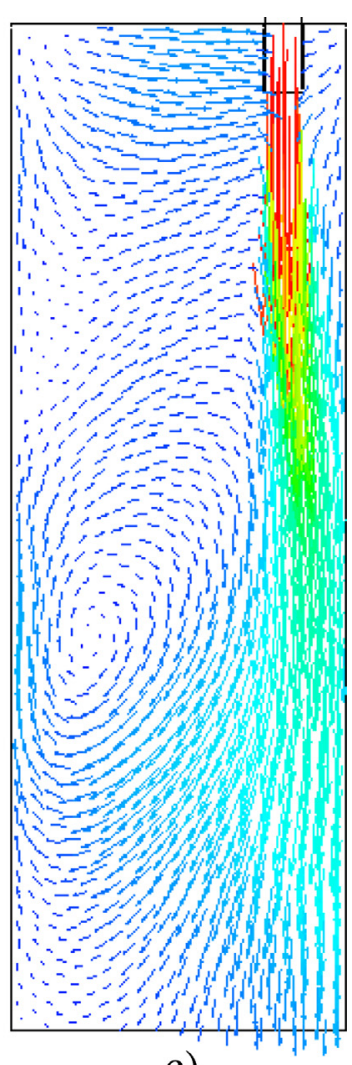

c)

$125 \mathrm{~L} / \mathrm{min}$

$150 \mathrm{~L} / \mathrm{min}$

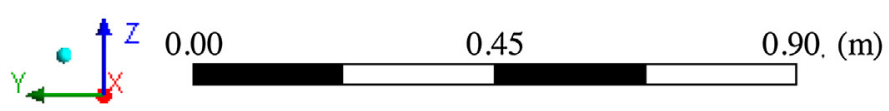

Fig. 11. CFD simulations of flow field at web symmetry plane AA, type 3 nozzle under flow rates of: (a) $100 \mathrm{~L} / \mathrm{min}$, (b) $125 \mathrm{~L} / \mathrm{min}$ and (c) $150 \mathrm{~L} / \mathrm{min}$.

flange and later it is engulfed by the downward fluid jet. At the plane BB, Fig. 12(a)-(c), formation of four eddies can be noticed. Two of them down in the mold are also caused by the spreading of the jet and the others close to the nozzle are formed due to the meeting of the fluid stream on the free surface with the fluid engulfed by the jet. Eddies also appear in the upper region at the opposite side of the tubular valve-plane CC, Fig. 12(d)-(f). These are formed due to interaction between the upstream flow with the flow in the region of the meniscus.

Fig. 13 shows the movement of dispersed plastic particles inside the mold as a function of time after injection. The particles have been lit by a laser sheet. The jet can be considered completeley developed after some $12 \mathrm{~s}$ since the particles are completely dispersed in the mold. Here also there is evidence for existance of the vortex already shown in Fig. 11. The extension and location of this vortex structure have been very well predicted by CFD simulations. Also it is clear that the jet stream goes deep down to $0.8 \mathrm{~m}$ before returning to the upper portion of the mold through the opposite flange.

A comparison of meniscus velocities for a linear casting speed of $0.98 \mathrm{~m} / \mathrm{min}$ and for the cases of one and two nozzles shows no remarkable difference. The maximum values are $0.15 \mathrm{~m} / \mathrm{s}$ and $0.17 \mathrm{~m} / \mathrm{s}$, respectively. This is smaller than a limiting value of $0.3 \mathrm{~m} / \mathrm{s}$ suggested by De Santis et al. (2014). For one nozzle configuration the maximum value can be found at the region ranging from the web to the filets close to the nozzle, as it can be seen from Fig. 14(a) and (b). In the case of two nozzles, the maximum values are at the fillets, Fig. 14(d). Velocities at the web center are as high as $0.09 \mathrm{~m} / \mathrm{s}-$ Fig. 14 (c). According to Chen et al. (2012a) too low meniscus velocity can lead to a low powder melting rate. Xu and Zhu (2015) observed that lower temperatures and an inactive meniscus status induced by the straight SEN affect adversely the melting the powder flux and consequently the product quality. Beaton et al. (2015) tested one valve designed with two pouring holes, one at the bottom and other at the lateral side facing the web. These authors found that with this SEN, the combined effect of even powder feeding and a stable meniscus, resulted in a smooth surface of the product, without superficial holes.

The higher values of velocity in the region between the filet and the nozzle can lead to thinner steel shell at this region. According to Yang et al. (2004) the filet region is prone to thinner shells. The non-symmetrical flow and the velocity differences between the filet flow regions can lead to shells of different thickness at the fillets.

\section{Conclusions}

Generally speaking there is a good agreement between the results obtained from physical model using PIV technique and CFD modelling. This means that CFD modeling technique can be used for this type of process analysis. The following conclusions can be reached in respect of results obtained for two nozzles arrangement and the single nozzle arrangement:

\subsection{Two nozzles, symmetrical flow}

- Physical modeling shows a strong influence of liquid flow rate on the jet penetration depth. CFD analysis shows a lesser influence 


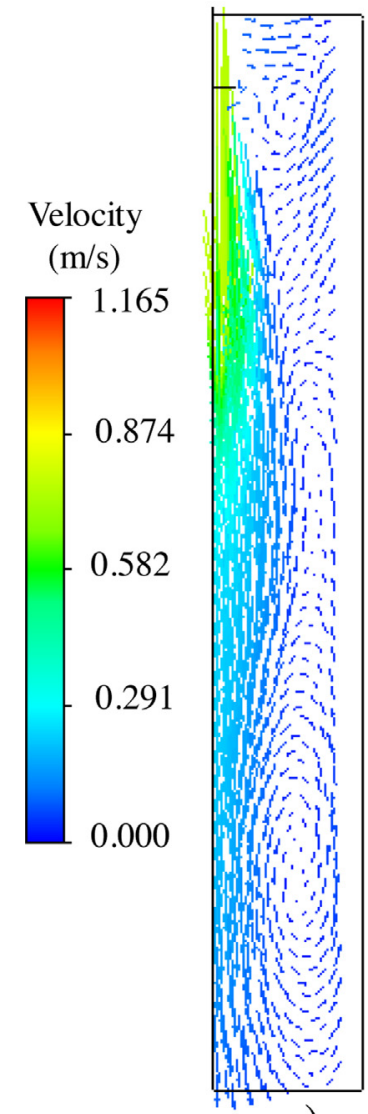

a)

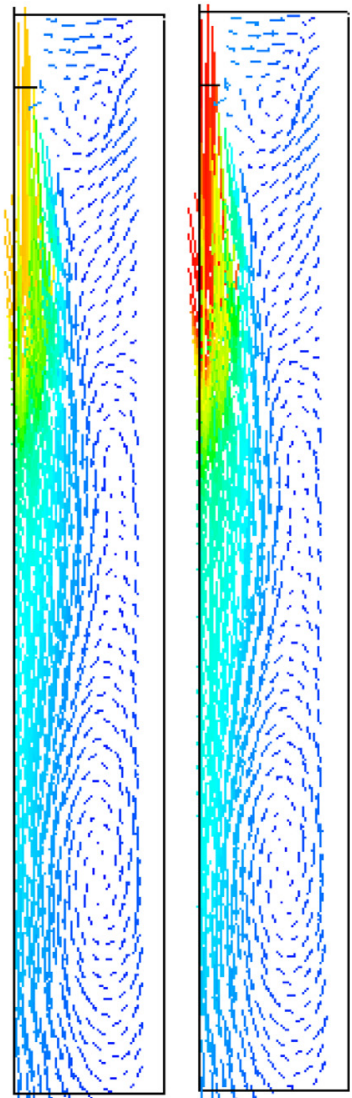

b)

c)

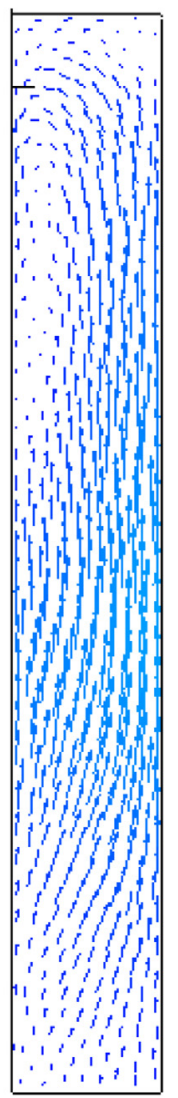

d)

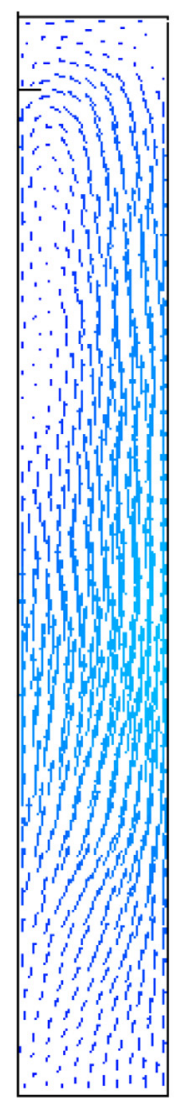

e)

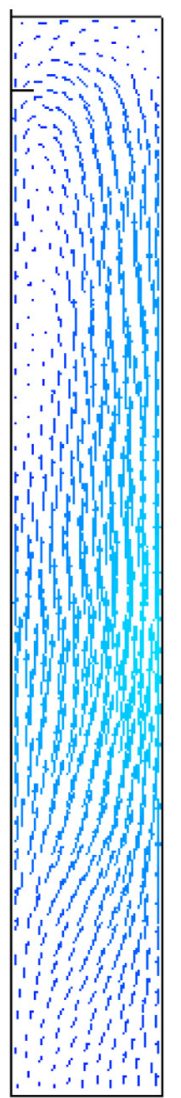

f)

$100 \mathrm{~L} / \mathrm{min} 125 \mathrm{~L} / \mathrm{min} \quad 150 \mathrm{~L} / \mathrm{min} \quad 100 \mathrm{~L} / \mathrm{min} \quad 125 \mathrm{~L} / \mathrm{min} \quad 150 \mathrm{~L} / \mathrm{min}$

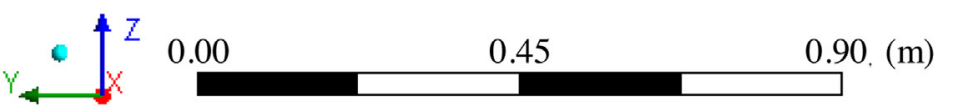

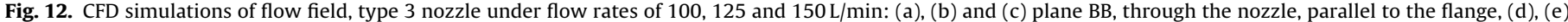
and (f) plane CC, parallel to opposite flange, $250 \mathrm{~mm}$ from it.

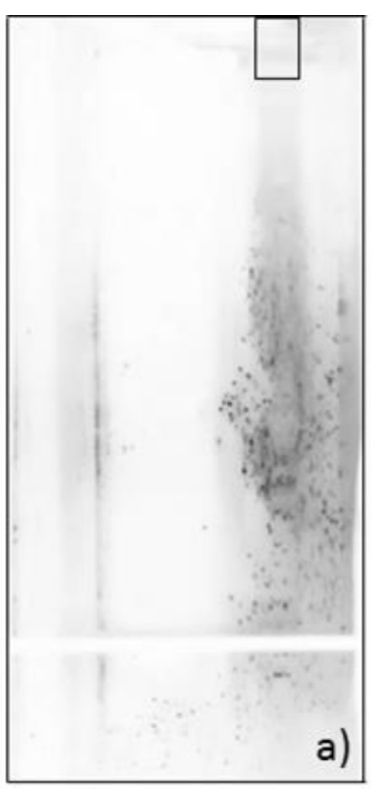

$125 \mathrm{~L} / \mathrm{min}-4 \mathrm{~s}$

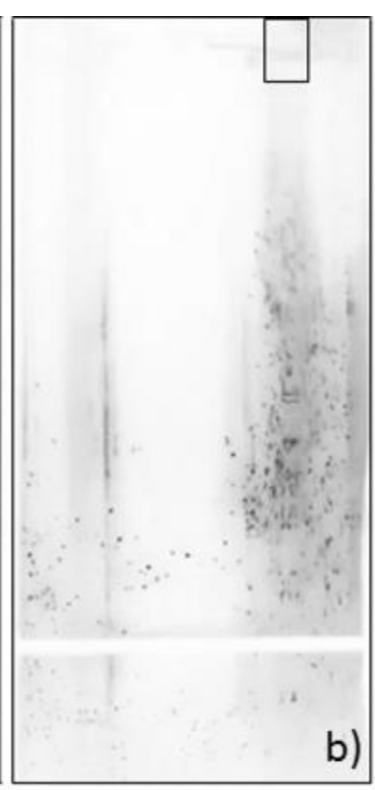

$125 \mathrm{~L} / \mathrm{min}-8 \mathrm{~s}$

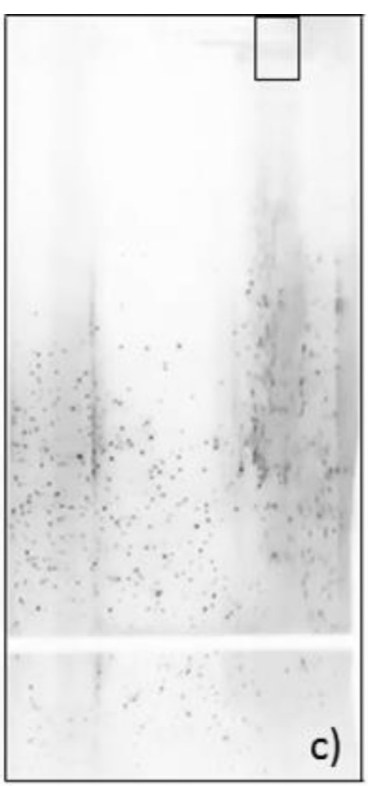

$125 \mathrm{~L} / \mathrm{min}-12 \mathrm{~s}$

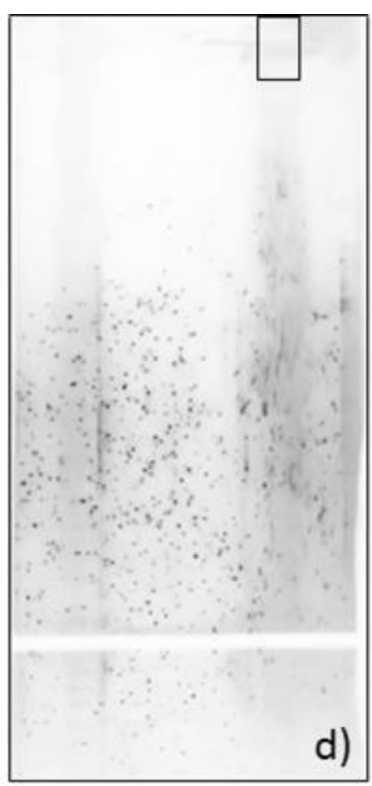

$125 \mathrm{~L} / \mathrm{min}-16 \mathrm{~s}$

Fig. 13. Flow visualization of dispersed particles in a beam blank mold under flow rate of $125 \mathrm{~L} / \mathrm{min}$ : (a) $t=4 \mathrm{~s}$; (b) $t=8 \mathrm{~s}$, (c) $t=12 \mathrm{~s}$ and (d) $t=16 \mathrm{~s}$. 

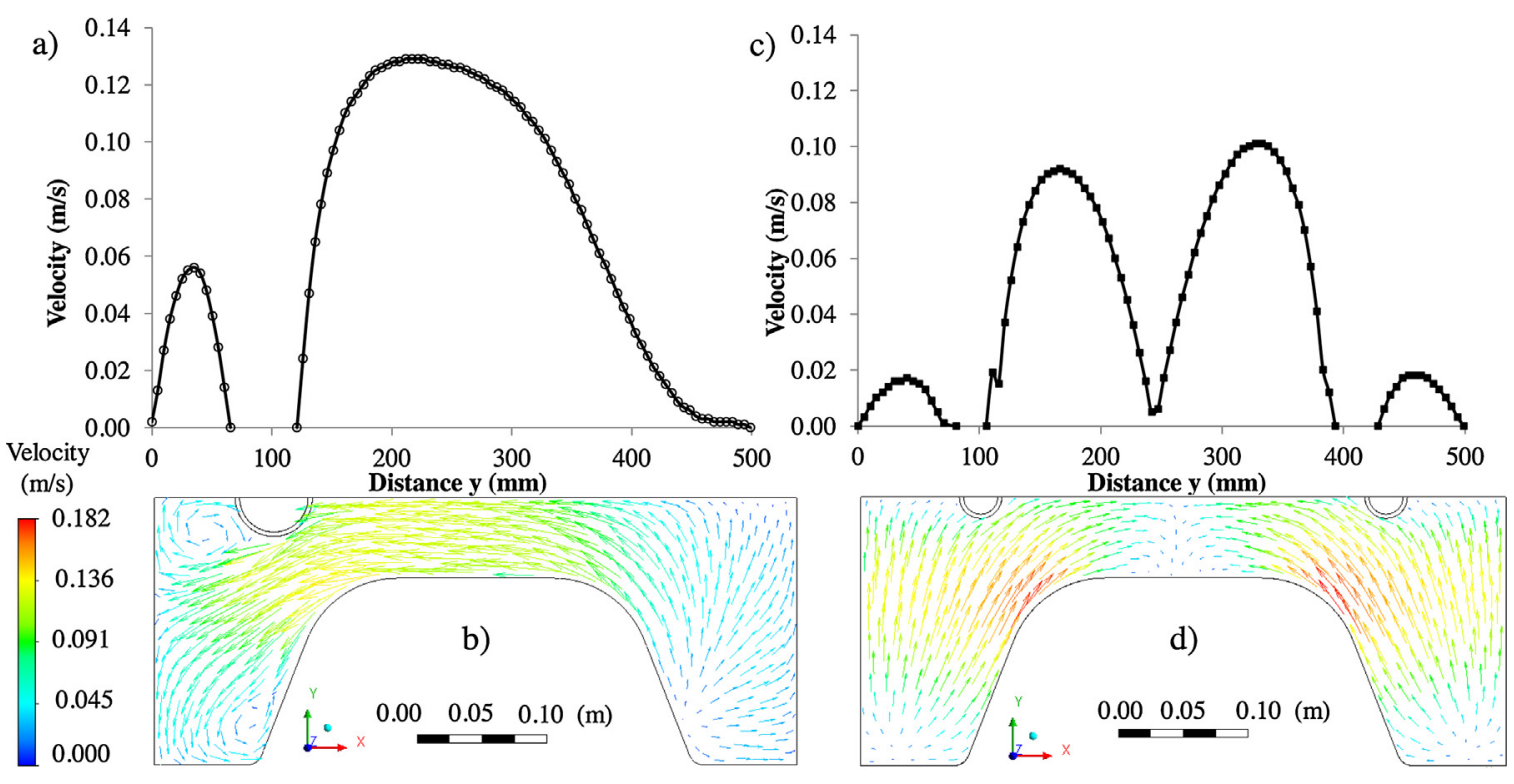

Fig. 14. Velocity values the meniscus: (a) type 1 nozzle, (b) type 3 nozzle. Velocity vector plot at meniscus: (c) type 1 nozzle, (d) type 3 nozzle. Flow rate of 125 L/min.

of the flow rate. However the results are comparable with the physical model experiments.

- There is no significant change in the behavior of the fluid flow when the nozzle inside diameter is changed from $26.7 \mathrm{~mm}$ to $34.6 \mathrm{~mm}$. Enlarging the nozzle diameter on $68 \%$ did not result on sizable reduction of the jet penetration depth.

- The recirculation of fluid generates two eddies in the region of the web and two in each flange.

\subsection{One nozzle non-symmetrical flow}

- Jet penetration depth with flow rates of $100 \mathrm{~L} / \mathrm{min}, 125 \mathrm{~L} / \mathrm{min}$ and $150 \mathrm{~L} / \mathrm{min}$ were $0.92 \mathrm{~m}, 1.19 \mathrm{~m}$ and $1.29 \mathrm{~m}$, respectively. These values are larger than mold nominal length $(0.8 \mathrm{~m})$;

- There is a recirculation eddy down in the mold and at plane BB four eddies could be noticed;

- Non-symmetrical flow and velocity differences between the filet flow regions suggest shells of different thicknesses at the fillets.

\section{Acknowledgement}

The authors wish to acknowledge the help provided by the research institutions in Brazil namely CNPq, CAPES, Fundação Gorceix and FAPEMIG.

\section{Appendix A. Supplementary data}

Supplementary data associated with this article can be found, in the online version, at http://dx.doi.org/10.1016/j.jmatprotec.2016. 02.011 .

\section{References}

Beaton, J.W., Sgro, A., Burini, A., Razza, P., Azizola, Ali., 2015. Beam blank in submerged pour casting: Danieli technology and experience. In: Proceedings of METEC and 2nd ESTAD Conference, Düsseldorf, Germany, pp. 15-19.
Chen, W., Zhang, Y.Z., Zhu, L.-G., Zhang, C.-J., Chen, Y., Wang, B.X., Wang, C., 2012a. Three dimensional FEM study of fluid flow in mould for beam blank continuous casting: influence of straight through conduit type SEN. Ironmak. Steelmak. 39 (8), 551-559

Chen, W., Zhang, Y.Z., Zhang, C.J., Zhu, L.G., Zhang, C.J., Chen, Y., Wang, B.X., Wang, C., 2012b. Three-dimensional FEM study of fluid flow in mould for beam blank continuous continuous casting: influence of nozzle structure and parameters on fluid flow. Ironmak. Steelmak. 39 (8), 560-567.

De Santis, M., Cristallini, A., Rinaldi, M., Sgro, A., 2014. Modelling-based innovative feeding strategy for beam blanks mould casting aimed at as-cast surface quality improvement. ISIJ Int. 54 (3), 496-503.

Hibbeler, L.C., Xu, K., Thomas, B.G., Koric, S., Spangler, C., 2009. Thermomechanical modeling of beam blank casting. Iron Steel Technol. 6 (7), 60-73.

Lee, J.-E., Yoon, J.-K., Han, H.N., 1998. 3-dimensional mathematical model for the analysis beam blank casting using body fitted coordinate of continuous system. ISIJ Int. 38 (2), 132-141.

Lee, J.-E., Yeo, T.-J., Oh, K.H., Yoon, J.-K., Yoon, U.-S., 2000. Prediction of cracks in continuously cast steel beam blank through fully coupled analysis of fluid flow, heat transfer, and deformation behavior of a solidifying shell. Metall. Mater. Trans. A 31A (1), 225-237.

Li, B., Okane, T., Umeda, T., 2001. Modeling of biased flow phenomena associated with the effects of static magnetic-field application and argon gas injection in slab continuous casting of steel. Metall. Mater. Trans. B 32B (6), 1053-1066.

Szekely, J., Ilegbusi, O.J., 1989. The Physical and Mathematical Modelling of Tundish Operations. Springer-Verlag, New York, pp. 34-38.

Xu, M., Zhu, M., 2015. Transport phenomena in a beam-blank continuous casting mold with two types of submerged entry nozzle. ISIJ Int. 55 (4), 791-798.

Yang, J-w., Du, Y-p., Shi, R., Cui, X-c., Liu, C., 2004. Effect of SEN parameters on 3D flow field in mould of beam blank continuous casters. J. Iron Steel Res. Int. 11 (6).

Yang, J.W., Du, Y.P., Shi, R., Cui, X.C., 2006. Fluid flow and solidification simulation in beam blank continuous casting process with 3D coupled model. J. Iron Steel Res. Int. 13 (4), 17-21.

Zhang, L., Chen, D., Long, M., Xie, X., Zhang, X., Ma, Y., 2014. Hydraulic simulations of fluid flow in beam blank casting mold with double nozzles. In: Yurko, J., Zhang, L., Allanore, A., Wang, C., Spangenberger, J.S., Kirchain, R.E., Downey, J.P., May, L.D. (Eds.), Proceedings of EPD Congress 2014. Hoboken, NJ, USA, pp. 375-384.

Zhao, Y., Chen, D.F., Long, M.J., Shen, J.L., Qin, R.S., 2014. Two-dimensional heat transfer model for secondary cooling of continuously cast beam blanks. Ironmak. Steelmak. 41 (5), 377-386. 